\title{
I I I \\ Sociedades anônimas -0 direito do acionista de anular as deliberações da Assembléa Geral
}

\author{
Jorge Americano
}

\begin{abstract}
Quatro accionistas, A. B. C., e D eram directores e titulares da quasi totalidade das acções de uma sociedade anonyma, que chamaremos "Fabrica". Ao mesmo tempo os quatro eram socios solidarios de uma sociedade commercial que chamaremos "Firma".

A "Fabrica" deu á "irma" "exclusividade" para a venda de toda a sua producção. Por outras palavras A, B, C, e D eram os unicos vendedores dos productos da "Fabrica" da qual elles proprios eram directores.
\end{abstract}

Fallecendo A os seus herdeiros foram excluidos da Firma, por uma liquidação da qual não puderam fugir. Tambem foram excluidos da direcção da Fabrica. Estão, ademais, em minoria, juntos com outros titulares de pequeno numero de acções.

Não consta a existencia de um contracto entre a "Fabrica" e "Firma" e segundo parece esse regimem 
existe em virtude da deliberação simples, e continúa, em virtude da pratica já velha desse regimem. Tambem não consta qualquer approvação especial da assembléa dos accionistas.

Os socios B, C e D pois, livres dos herdeiros de A na "Fabrica" e na "Firma", estão á vontade. Sem que a "Firma" seja productora, entrou ella para um convenio de productores, e, por preços altos e vantajosos (para a firma) entregou a terceiros a distribuição dos productos da "Fabrica", emquanto que esta, pela entrega de toda a sua producção á "Firma" percebe um lucro minimo, D'outro geito B, C e D ganham atravez da "Firma" os lucros reaes da producção da "Fabrica", emquanto que os herdeiros de A excluidos da "Firma", só recebem a titulo de dividendo, a parcella minima dos lucros colhidos pela "Fabrica".

A "Fabrica" actualmente vale umas 8 ou 10 vezes mais, e apezar disso não foram emittidas novas acções. $\mathrm{O}$ dividendo pago aos herdeiros de $\mathrm{A}$, não corresponde ao valor actual da "Fabrica" e sim de accordo com o valor da fundação desta.

Continuando ha mais de 15 annos com este systema, os socios B, C e D augmentaram muito os negocios da "Firma", comprando mais industrias em varias cidades, grandes glebas de terrenos, etc., augmentando consideravelmente, cada um delles, a sua fortuna particular, emquanto os herdeiros do socio A vivem da liquidação de propriedades que pertenceram particularmente a este. 
A "Firma" ha muitos annos empresta dinheiro á "Fabrica" mediante juros.

Os herdeiros desde a epoca em que herdaram as acções nunca approvaram os balanços — ou se abstiveram de votar, ou não compareceram ás assembiéas.

Pergunta-se :

$1 .^{\circ}$ - Os socios B, C e D, como directores, vendendo a si proprios (á Firma) os productos da "Fabrica" e emprestando elles mesmos dinheiros á "Fabrica", de que são directores, incorrem em violação das leis do paiz ?

2." - Se B. C e D pódem ser responsabilizados durante os ultimos annos passados por sua administração, e enriquecimento, em parte ás custas dos herdeiros de A ?

3. - Se B, C e D pódem ser obrigados por lei a emittir novas acções de accordo com o valor actual da "Fabrica".

4. - Tendo sido, em tempo, proposta uma acção fundada no direito das minorias, afim de por ella fazerem os socios lesados, cessar tal estado de coisas, pódem estes socios, no caso de lhes ser contraria a decisão, propor nova demanda com o mesmo intuito?

Com que fundamento legal ?

O caso da presente consulta foi estudada por Waldemar Ferreira, a quem se submetteu á questão em 1929, e consta da segunda série das suas Questões de Direito Commercial, pag. 70 .

A primeira pergunta que os consulentes lhe submetteram foi assim redigida: - Os herdeiros têm acção para annullar aquella exclusividade e para pedir aos directores as perdas e damnos (decr. 434 , art. $112 \S 1 .^{\circ}$ ) ?

Opinou aquelle professor:

"Respondo negativamente. Carecem os accionistas de tal acção. E carecem della por varios motivos. Primeira- 
mente, porque os directores, fazendo o contracto que fizeram, agiram dentro dos poderes inherentes aos cargos de que foram investidos. Depois, porque, sciente desse contracto, a assembléa geral dos accionistas não se oppoz á sua continuidade.

Podem os accionistas, em assembléa geral, dar instruções aos directores, no sentido de sustar o contracto de exclusividade, que não tem praso de duração marcado, passando a sociedade a vender os seus productos directamente, de sorte que passem os accionistas a participar de todos os lucros, que elles produzirem; e, em caso de inobservancia da deliberação da assembléa, destituil-os."

"Mas, argumenta-se, os accionistas, que divergem da orientação da directoria, são em numero sufficiente para a approvação de uma medida de tal natureza. Serão, acaso, obrigados a acceitar a pratica de um contracto que lhes é prejudicial ? Si o não podem annullar, pela inexistencia de qualquer motivo de ordem legal, que o invalide, poderão entretanto, exigir que os directores os indemnizem do prejuizo, que estão soffrendo?

Definiu a lei a responsabilidade dos administradores, com estabelecer, no art. 109 que elles são responsaveis: á sociedade, pela negligencia, culpa ou dolo, com que se houverem no desempenho do mandato; á sociedade e aos terceiros prejudicados, pelo excesso de mandato; solidariamente á sociedade e aos terceiros prejudicados, pela violação da lei e dos estatutos.

Não incluiu no texto o accionista, para dizer, em artigo. especial, o art. 110, que elle tem sempre salva a acção competente para haver dos administradores as perdas e damnos resultantes da violação da lei e dos estatutos.E accrescentou, no art. 111, que "a acção poderá ser intentada conjunctamente por dois ou mais accionistas, não podendo, porém, referir-se a actos e operações já julgados por assembléas geraes.

Como o contracto de exclusividade não viola os estatutos, nem a lei, e são communs na vida industrial, tambem não poderá o accionista, em razão delle e allegando os prejuizos 
delle resultantes, pedir a indemnisação de perdas e damnos. Por isso, e notadamente porque tendo a assembléa geral poder para resolver todos os negocios (art. 128), tomar quaesquer decisões e deliberar, approvar e ratificar todos os actos que interessem á companhia - bem poderá ella approvar ou ratificar o contracto de exclusividade, sem necessidade de modificar os estatutos, ou de mudar ou transformar o objecto essencial da sociedade"

Da leitura deste parecer me convenci que, tal como foi formulada a consulta ao prof. Waldemar Ferreira, e dentro do systema da lei das sociedades anonymas, tambem eu o subscreveria.

Mas note-se o seguinte:

Da consulta e do parecer, se vê que a solução dada assenta nestes presuppostos:

a) de que os directores agiram dentro dos poderes dos seus cargos;

b) de que a assembléa não se oppoz ao acto dos directores;

c) de que a minoria, sujeita á maioria, está obrigada a acceitar a maioria, quanto aos actos que esta julga convenientes aos interesses da sociedade, de vez que não violem a lei, nem os estatutos;

d) e, finalmente, de que, embora os directores sejam responsaveis pelas violações da lei ou dos estatutos, a approvação da assembléa geral os põe inteiramente a coberto da acção que assiste á minoria, para pedir perdas e damnos.

Entretanto, penso que teria havido solução diversa, si a consulta viesse proposta como o veiu agora.

De facto. $O$ que se imputa aos directores, imputa-se tambem á maioria, conluiada aos mesmos. Trata-se de uma directoria que, com o assentimento da maioria, constituindo todos uma firma social fóra da sociedade anonyma, praticam, por via dessa firma, aquillo que lhes seria impossivel praticar dentro do systema rigido da lei das sociedades anonymas: - a quebra da egualdade dos dividendo das acções, a beneficio da maiuria, oom damno para a minoria. 
Narra $o$ consulente que os accionistas formando maioria desviaram para a escripta da firma todo ou quasi todo o lucro da fabrica; de sorte que, auferindo pela firma, só elles, o que a todos cabia pelos lucros da fabrica, lesam continuamente á minoria, que se veria suffocada pela maioria na assembléa geral, ao fazer, sobre o caso, qualquer. reclamação.

Ora, o principio da egualdade de lucros entre os accionistas é intangivel. Cada accionista de acção integralizada percebe pela sua acção o mesmo que cada um dos outros. Este principio assenta no art. 330 do Codigo Commercial, que diz: Os ganhos e perdas são communs a todos os socios na razão proporcional dos seus respectivos quinhões no fundo social; salvo se outra cousa fôr expressamente estipulada no contracto.

$\mathrm{Na}$ sociedade anonyma, o quinhão é composto de acções, e os dividendos representam os ganhos. E a lei das sociedades anonymas não revogou o Codigo Commercial, quanto á egualdade dos ganhos, que, na hypothese, pode-se exprimir, a egualdade dos dividendos das acções de egual volor e emissão identica (resalvadas as preferencias, acções fraccionadas, etc.).

Portanto, si é certo que o acto da administração, a que a minoria seja contraria, acoberta-se pela approvação da maioria, tambem é certo que a maioria está obrigada a respeitar o principio fundamental, da equivalencia das quotas, constituida pela egualdade dos dividendos.

A maioria que approvasse disposição impondo a cada accionista da minoria receber menores dividendos que os percebidos por ella, maioria, ver-se-ia constrangida pelos tribunaes a soffrer a decretação da nullidade dessa deliberação, por ter objecto illicito, Codigo Civil, art. 145, n. II. A acção que, para esse fim, lhe seria dada pela lei, fundar-seia, não na lei das sociedades anonymas, e sim no Codigo Civil, arts. 145 n. II, 159 e 1518.

E' que não são só as acções mencionadas na lei das sociedades anonymas, as que competem ao socio. Aquellas 
são as que lhe competem pelo systema do instituto dessas sociedades. Porém, esse instituto está subordinado aos principios geraes de direito, firmados na parte geral do Codigo Civil, condemnatorios do dolo, e reintegradores da violação. Na hypothese acima figurada, nenhum juiz se negaria a cancellar a deliberação da assembléa, nem exigiria que o pedido se fundasse na lei das sociedades anonymas.

Bastar-lhe-ia a indicação do texto legal violado, e elle applicaria o principio geral do direito civil, extensivo ao direito commercial.

Estabelecido isto, cumpre considerar, entretanto, que em ninguem, notadamente na gente do commercio, será possivel presumir tamanha ingenuidade na violação da lei, que seja praticada declarando frente a frente que a lei deve ser violada. Ordinariamente, a violação se faz sempre a coberto de um texto que lhe dá fórma licita.

Assim, o marido que quer fazer doação a concubina, e simula venda, vê cancellado o seu acto; assim tambem, si fizesse doação a terceiro, para que este a fizesse á concubina. Seriam sempre actos em fraude da lei, actos de forma licita para encobrir o illicito.

Si se faz pacto expresso sobre herança de pessôa viva, esse pacto é nullo. Não deixará de o ser, si se procurar uma forma valida para empenhar sua herança. A difficuldade de provar que determinado contracto de forma valida encobre um pacto sobre herança de pessôa viva, já é questão diversa. O que cumpre estabelecer sempre, é o principio que manda considerar nullo o acto que tem por objecto, claro ou oculto, pactuar sobre herança de pessôa viva. E' sempre um acto doloso, pois que fraudatorio da prohibição legal.

A lei não prohibe sómente o que lhe viola as intenções, fazendo affirmações contrarias ao seu texto. A lei vae perseguir a immoralidade consistente no acto doloso, para cancellar os seus effeitos, onde a encontrar provada, ainda que occulta nas malhas do acto licito. 
Em obra que publiquei (Acção Pauliana, n. 55) escrevi o seguinte: "A fraude jamais se estipula, e quando se commette em prejuizo de outrem, desmascaral-a para tornal-a impotente é direito incontestavel de legitima defesa. A apparencia do acto licito não deve deter, portonto, a apreciação meticulosa das circumstancias, a pesagem dos indicios, o confronto dos factos, para que a perfectibilidade da fraude não seja factor da sua validade"

E' que a lei nâo tem o fetichismo das formas. Sua finalidade é mais alta. Visa assegurar, na vida de cada instituto juridico, o respeito aos principios dominadores de toda a legislação, em cuja cupula se inscrevem o repudio ao dolo, a protecção ao honesto. Si não obedece ao rigor de uma definição, em todo caso representa um postulado juridico o conceito latino do honestè vivere, alterum non laedere, suum cuique tribuere. 0 direito não pode acoroçoar, e effectivamente não acoroçôa que se viva deshonestamente, ou que se lése aos outros, sob a capa das formulas juridicas licitas, como sejam a constituição de uma sociedade anonyma, a formação de uma sociedade commercial, e a outorga por aquella a esta, da exclusividade da venda dos seus productos.

São todos, actos licitos.

Mas, ao ouvir a narrativa de que a maioria de uma sociedade anonyma, no exercicio do seu direito, vae constituir tambem no exercicio do seu direito, uma sociedade ou firma commercial, cujo fim é vender todos os productos daquella sociedade, finalidade tambem perfeitamente licita, toda gente dirá: si a maioria age assim, e si desta acção resulta ficar a minoria privada da egualdade dos dividendos (porque a maioria vae interceptal-os na firma, antes que elles possam entrar nos lucros da sociedade anonyma), trata-se, manifestamente, de um acto immoral.

$O$ que se pede, no caso, ao jurista, não é que defina o acto como immoral, que para isso basta o senso commum.

Pede-se-lhe que cancelle a immoralidade, com os meios de direito. Para tanto, basta considerar as circumstancias 
do caso, e approximal-as do texto do art. 330 do Codigo Commercial que assegura a egualdade dos lucros.

E' licito, e é até commum, dividirem-se as actividades, separando a funcção de produzir da de distribuir a riqueza, de modo a acompanhar juridicamente a selecção das actividades economicas.

Mas, si se procurar em hypothese concreta, os moveis dessa divisão das actividades, constata-se nella:

a) que a divisão das actividades é ficticia, porque a mesma maioria da sociedade anonyma é que compõe a firma commercial;

b) que não é normal em uma industria, de natureza lucrativa, despir-se o industrial da maior parte dos seus lucros, para se contentar com vantagens tão minimas, que se torne devedor dos vendedores, repletos estes com os lucros do trabalho d'aquelle;

c) que, entretanto, tal situação se explica, ás vezes, pela inaptidão commercial do productor, em face da habilidade desenvolvida pelo collocador dos productos no mercado; mas não se pode explicar quando productor e consumidor são a mesma pessôa, (hypothese aliás inverificavel, por falta de interesse em dividir-se em duas a actividade que pode ser exercida sob a feição unitaria) nem se pode explicar quando, do productor, entidade formada de individuos, se destacam alguns para formar uma firma, que percebe todos os lucros;

d) que a circumstancia de proceder a maioria, na sua qualidade de maioria, á approvação dos actos da directoria, realisados com outra entidade que é formada pelos mesmos individuos componentes da maioria, alliada á circumstancia de que estes actos são beneficos a ella e damnosos á minoria, induz o dolo em taes actos;

e) que o individuo que tem certa qualidade, não pode, nessa qualidade, intervir em actos que o beneficiam em outra qualidade, sem infringir os preceitos da moral ordinaria e, em havendo damno, ser constrangido, ou a desfazer o acto, ou a recompor o damno. Não é baseada em princi- 
pio diverso a regra de direito publico que véda ao administrador contratar com a administração em que é parte; a que véda ao tutor ou curador adquirir, por si ou por interposta pessôa os bens do tutelado ou curatelado, etc.

f) que si, como affirma o consulente, a firma absorve a quasi totalidade dos lucros, ao passo que a sociedade anonyma vae sempre em más finanças; si a maioria é, de facto, a componente da firma; si a minoria percebe dividendos ridiculos em face dos que percebe a maioria nessa qualidade de componente da firma - achamo-nos, indiscutivelmente, em face de um caso de dolo, occulto nas malhas de actos licitos. Mesmo que se não conseguisse provar que a firma se fundou com finalidade dolosa (Cod. Civil, art. 92), ficaria estabelecido que, formada mesmo sem dolo, e a despeito da finalidade de quebrar a egualdade dos dividendos, a firma está servindo a este fim (dolo accidental, Cod. Civil, art. 93), e os prejudicados têm acção de perdas e damnos.

A acção, é, pois, a actio doli, mencionada por Corrêa Teles, Doutrina das Acções, $\S$ 444, fundada no art. 93 do Codigo Civil, combinado com os arts. 159 e 1518, quando não possa ser mesmo a acção de annullação, desde que se não possa firmar o dolo essencial do art. 92 do Codigo Civil. Seu fundamento é a violação do art. 330 do Codigo Commercial.

Fica, assim, respondido o primeiro quesito da consulta.

Do exposto na resposta ao quesito anterior fica subentendido que todos os que intervieram nos actos dolosos, como todos os que participaram nos lucros podem ser responsabilisados, solidariamente com a fabrica e a firma. A citação destas, conjunctamente com a de cada socio da firma, faz-se necessaria, não só pela solidariedade no dolo, como, praticamente, para o exame nos livros de ambas. Assim respondo ao segundo quesito. 
Não podem os accionistas da maioria ser obrigados a emittir novas acções, porque a emissão é prerogativa da maioria, em assembléa geral. Todavia, desde que persista a situação descripta na consulta, persiste o direito do consulente á indemnisação, o que suppre a impossibilidade que tem a minoria, de forçar a maioria á emissão. Fica respondido o terceiro quesito.

A litispendencia assenta na identidade de coisa (finalidade juridica visada pelo autor) de causa (fundamento juridico do pedido) e pessôas (partes na demanda ou seus successores). Veja-se o art. 229 do Codigo do Processo.

A falta de uma destas identidades, já autoriza a propositura de outra demanda, embora o objecto pedido seja seja o mesmo.

No caso presente, não se diria que a acção que tem por objecto annullar um contracto praticado pela directoria, com o consenso da maioria, terá o mesmo objecto que a acção tendo por objecto annullal-o por fraude aos termos da lei. Principalmente se verifica o objecto diverso, si a acção fôr proposta tendo em mira sómente a indemnisação, conforme o art. 93 do Codigo Civil.

Entretanto, admittindo que o objecto possa entender-se em ambas o mesmo, o certo é que o fundamento é diverso.

A identidade de fundamento é estudada por Lacoste, quando estuda a cousa julgada. Mas, como litispendencia e cousa julgada têm o mesmo fundamento na triplice identidade (Cod. do Processo, art. 229), o que diz Lacoste relativamente á cousa julgada, applica se, mutatis mutandis, á litispendencia: 
Pedir a nullidade de um acto sob a arguição de dolo, não é invocar, de um modo geral, a ausencia de consentimento, nem a incapacidade, com arguir a menoridade, ou a irregularidade geral de fórma oom denunciar determinado vicio formal. As conclusões da causa, quaes ficam individuadas na contestação da lide, — ou dolo, ou erro, ou violencia, ou menoridade, ou interdicção, ou falta de uma testemunha, ou raspadura em passagem essencial do instrumento, etc., etc. - só ellas, uma por uma, constitúe fundamento distincto. Cada vicio, cada causa distincta. "Autant des vices l'on aura à faire valoir, autant on pourra former de demandes" (Lacoste, De la Chose Jugée, n. 400).

Pela ligeira menção que se faz na consulta, e pelo parecer do dr. Waldemar Ferreira, parece-me que a demanda ajuizada não alcançará procedencia. Mas. ella não impede a propositura de nova demanda sobre o mesmo fim, porque o fundamento é diverso.

São Paulo, 27 de Agosto de 1934.

S. M. J. 